\title{
Examining the Attacks After the 20th Scores in Volleyball According to Nationality and Positions
}

\author{
Cengiz Akarcesme ${ }^{1}$, Muhammed Sahin ${ }^{2}$, Yaprak Kalemoğlu Varol ${ }^{1} \&$ Filiz Fatma Colakoglu ${ }^{1}$ \\ ${ }^{1}$ Sport Sciences Faculty, Gazi University, Turkey \\ ${ }^{2}$ Institute of Health Sciences, Gazi University, Turkey \\ Correspondence: Cengiz Akarcesme, Sport Sciences Faculty, Gazi University, Abant Sokak No: 12, Ankara, \\ Turkey.
}

Received: September 14, 2018

Accepted: October 10, $2018 \quad$ Online Published: October 23, 2018

doi:10.5539/jel.v7n6p184

URL: https://doi.org/10.5539/jel.v7n6p184

\begin{abstract}
The most efficient technique of scoring in volleyball is possible to be mentioned as attack. The numbers of efficient attacks performed after the $20^{\text {th }}$ scores during the match are more important, and therefore this period should be managed more elaborately in terms of the technique and tactic. Therefore, it is considered that players' presenting more productive performances with the drills related to the match after the trainings will be more efficient upon winning the match.

The purpose of this study was to investigate the attacks performed after the $20^{\text {th }}$ scores in 2017-2018 Volleyball Sultans League session according to the nationalities and positions. The study included totally 124 female players with natives $(n=86)$ and foreigners $(n=38)$ from 12 teams between 26 and 30 years old $(28.25 \pm 1,62)$. The numbers of the attacks performed after the $20^{\text {th }}$ scores of 17.918 rallies in 496 sets (except from the $5^{\text {th }}$ set) of 125 matches played by 12 teams during the session were evaluated. All matches were recorded with a video recorder by the researcher. The videos were analyzed by the experts in 3 repetitions. Attack errors, blocked attack, bad attacks, good attacks, numbers of attacks, coverage and totals numbers of attacks performed after the $20^{\text {th }}$ scores during the match were recorded in numbers. Lilliefors Kolmogorov-Smirnov Test indicated whether the study data were appropriate for the normal distribution or not $(\mathrm{p}<.05)$. In data analysis, descriptive statistics such as number, percentage, arithmetic average and standard deviation were used; and Independent Samples T-Test and One-Way Variance Analysis (One-Way ANOVA) were used for determining the difference between dependent and independent variables. Tukey HSD Post-Hoc test was performed for finding among which groups there were differences between the units in one-way variance analysis (ANOVA). While interpreting the data, 0.01 and 0.05 were accepted as the level of significance. The research data were analyzed using SPSS 21 statistical software.

As result of the findings obtained in the study, it was determined that there were significant differences in whole attacks performed by the players in terms of nationalities and positions $(p<0.05)$. In conclusion, because the $20^{\text {th }}$ scores are referred the critic period called as the golden scores, foreigners and opposite spiker's that had high level conditional abilities for winning had more attacks.
\end{abstract}

Keywords: Attack efficiency, nationality, position, golden rallies, score

\section{Introduction}

Volleyball is a dynamic sport depending upon intermittent jumps, short sprints, strength, dynamism, flexibility, endurance, and leaping blocks and attacks without depending upon time with a high tempo (Puhl, Case, Fleck, \& Van Handel, 1982; Bazyler et al., 2018). Average working-resting rate in a volleyball match varied between 1 and $1: 1$, and the matches can go on for 2-3 hours depending upon the number of sets including resting periods for 11-15 seconds (Bazyler et al., 2018).

In volleyball, there are several movements apart from shooting the ball we perform with the members of our body during the match. The players should take the right position on both vertical and horizontal axis. The movements that will be performed on horizontal axis before the attack provide the maximum opportunity for players to achieve the best result (Pérez Turpin, Cortell-Tormo, Suarez-Liorca, Chincilla-Mira, Cejuela-Anta, 2009; Alptekin, Acet \& Korkmaz, 2016). 
The most efficient technique of getting the score in volleyball is possible to be mentioned as attack. Therefore, one of the necessary basic physical abilities as being important for attacks and blocks is lower extremity muscle strength expressed with numerous jumps performed during the matches (Sheppard et al., 2008; Sheppard et al., 2007; Sheppard, Gabbett \& Stanganelli, 2009; Giannopoulos et al., 2017). The number of attacks after receiving the service and efficiency of receiving the service determines winning or losing the match. It has been reported that attack and block are the abilities that provides taking the most scores, and therefore these abilities should be focused during the trainings (Häyrinen \& Tampouratzis, 2012).

Each team tries to finish action of playing with a strong spike for winning the match. All movements of attack are necessary while preparing for the attack, and success and failure are the final elements of the movement. Spike could not be fully performed by the players who had no high-level conditional abilities. Cognitive properties, tactical knowledge and previous experiences are remarkable in terms of successful attacks. The chance for a successful attack increases when all these factors are developed at a high level and the teams use varieties of attacks including numerous group tactics (Frohner, 1989; Sentuna, 2005). In volleyball, the teams win most of the scores from the attacks; therefore, efficieny of the attack is one of the most important determinants of victory (Challoumas \& Artemiou, 2018).

In general, the attacks performed after the $20^{\text {th }}$ scores the rate for the attack efficiency can be mentioned as decreasing because of being in the golden number period for winning the match; however, the studies carried out on this are limited. Our purpose was to investigate the attacks performed after the $20^{\text {th }}$ attacks in volleyball according to the nationalities and positions.

\section{Method}

\subsection{Research Model}

Descriptive research model was used in the research. The attack errors, blocked attack, bad attacks, good attacks, numbers of attacks, coverage and total numbers of attacks performed after the $20^{\text {th }}$ scores in 2017-2018 volleyball Sultans League session were examined according to the nationalities and positions of the female players.

\subsection{Research Group}

The research group included 124 Turkish and foreign-national female players in the teams in 2017-2018 Sultans League session. The descriptive statistics related to the research group were presented in Table 1.

Table 1. The descriptive statistics related to the research group

\begin{tabular}{llll}
\hline Variables & Gender & N & \% \\
\hline \multirow{2}{*}{ Nationality } & Turkish & 86 & 69.4 \\
& Foreigner & 38 & 30.6 \\
\hline \multirow{4}{*}{ Position } & Hitter & 42 & 33.9 \\
& Opposite Spiker & 22 & 17.7 \\
& Middle Blocker & 41 & 33.1 \\
\hline Total & Setter & 19 & 15.3 \\
\hline
\end{tabular}

\subsection{Collection of Data}

The research data were obtained from 496 sets and 17.918 rallies during 22 weeks of 12 teams in Sultans League. Because the research topic included the attacks after the $20^{\text {th }}$ scores, the data of the $5^{\text {th }}$ set were excluded from the study. Data of the 124 players were included into the analysis for evaluating the attack data after the $20^{\text {th }}$ scores.

\subsection{Data Analysis}

The distribution was regarded before analyzing the data of the research. Lilliefors Kolmogorov-Smirnov test proved that data of the study were not appropriate for the normal distribution $(\mathrm{p}<.05)$. Histogram graphic and normal distribution curve were determined with Skewness ( +1 and -1$)$ and Kurtosis $(+2$ and -2$)$, and the analyses were performed according to this. In data analysis, descriptive statistics such as number, percentage, arithmetic average and standard deviation were used; and Independent Samples T-Test and One-Way Variance Analysis (One-Way ANOVA) were used for determining the difference between dependent and independent variables. Tukey HSD Post-Hoc test was performed for finding among which groups there were differences between the 
units in one-way variance analysis (ANOVA). While interpreting the data, 0.01 and 0.05 were accepted as the level of significance. The research data were analyzed using SPSS 21 statistical software.

\section{Findings}

The averages and standard deviation values related to the attack errors, blocked attack, bad attacks, good attack, numbers of attack, coverage and number of total attacks performed after the $20^{\text {th }}$ scores during the session by the volleyball players in the research group were presented in Table 2.

Table 2. The averages related to the attacks of the players during the session

\begin{tabular}{lccc}
\hline Variables & N & $\boldsymbol{M}$ & SD \\
\hline Attack Error & & 3.67 & 4.566 \\
Blocked Attack & & 3.77 & 4.286 \\
Bad Attack & 124 & 11.44 & 12.859 \\
Good Attack & & 5.86 & 6.416 \\
Number of Attacks & & 19.48 & 20.406 \\
Coverage & & 2.73 & 3.129 \\
Number of Total Attacks & 46.95 & 46.588 \\
\hline
\end{tabular}

When Table 2 was analyzed, it was noticed that the average of the attack errors performed by the players in all positions during the session was $3.67(\mathrm{Sd}=4.566)$, the average for the good attack was $5.86(\mathrm{Sd}=6.416)$, and the average for the bad attacks was $11.44(\mathrm{Sd}=12.859)$.

The analysis results related to the attack errors, blocked attack, bad attacks, good attack, numbers of attack, coverage and number of total attacks performed during the session by the volleyball players in the research group according to their nationalities were presented in Table 3.

Table 3. The attacks according to the nationalities of the players

\begin{tabular}{|c|c|c|c|c|c|c|c|}
\hline & Nationality & n & $M$ & SS & SD & $\mathbf{t}$ & $\mathbf{p}$ \\
\hline \multirow{2}{*}{ Attack Error } & Turkish & 86 & 2.44 & 4.036 & & \multirow{2}{*}{-4.907} & \multirow{2}{*}{$.000 *$} \\
\hline & Foreigner & 38 & 6.44 & 4.524 & & & \\
\hline \multirow{2}{*}{ Blocked Attack } & Turkish & 86 & 2.44 & 3.516 & & \multirow{2}{*}{-5.827} & \multirow{2}{*}{$.000^{*}$} \\
\hline & Foreigner & 38 & 6.76 & 4.401 & & & \\
\hline \multirow{2}{*}{ Bad Attack } & Turkish & 86 & 7.25 & 10.495 & & \multirow{2}{*}{-6.240} & \multirow{2}{*}{$.000 *$} \\
\hline & Foreigner & 38 & 20.92 & 12.794 & & & \\
\hline \multirow{2}{*}{ Good Attack } & Turkish & 86 & 3.50 & 4.402 & & \multirow{2}{*}{-7.393} & \multirow{2}{*}{$.000^{*}$} \\
\hline & Foreigner & 38 & 11.21 & 7.071 & & & \\
\hline \multirow{2}{*}{ Number of Attacks } & Turkish & 86 & 11.08 & 13.604 & & \multirow{2}{*}{-8.773} & \multirow{2}{*}{$.000 *$} \\
\hline & Foreigner & 38 & 38.50 & 20.581 & & & \\
\hline \multirow{2}{*}{ Coverage } & Turkish & 86 & 1.80 & 2.467 & & \multirow{2}{*}{-5.500} & \multirow{2}{*}{$.000^{*}$} \\
\hline & Foreigner & 38 & 4.81 & 3.478 & & & \\
\hline \multirow{2}{*}{ Number of Total Attacks } & Turkish & 86 & 28.52 & 35.181 & & \multirow{2}{*}{-8.230} & \multirow{2}{*}{$.000 *$} \\
\hline & Foreigner & 38 & 88.65 & 42.383 & & & \\
\hline
\end{tabular}

$* \mathrm{p}<0.05$.

When Table 3 was analyzed, it was determined that there were significant differences in all attacks performed by the Turkish players and foreign-national players $(\mathrm{p}<0.05)$. According to this, attack errors $\left(M_{\text {Turkish }}=2.44\right.$; $\left.M_{\text {foreigner }}=6.44\right)$, blocked attack $\left(M_{\text {Turkish }}=2.44 ; M_{\text {foreigner }}=6.76\right)$, and bad attacks $\left(M_{\text {Turkish }}=7.25 ; M_{\text {foreigner }}=20.92\right)$ of the Turkish players were found to be lower than the foreign-nationality players.

The analysis results related to the attack errors, blocked attack, bad attacks, good attack, numbers of attack, coverage and number of total attacks performed during the session by the volleyball players in the research group according to their positions were presented in Table 4. 
Table 4. Attacks according to the positions of the players

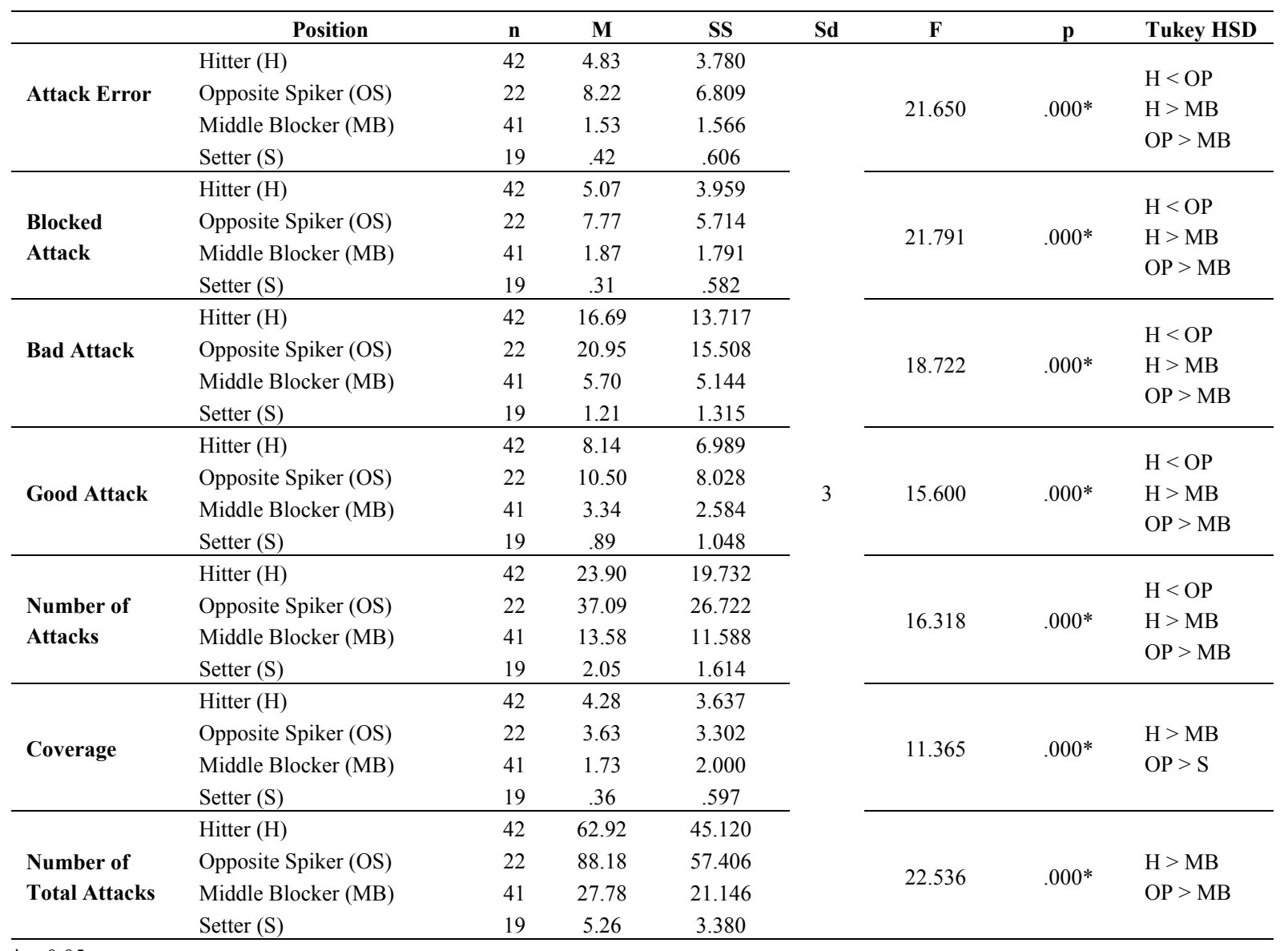

$* \mathrm{p}<0.05$.

When Table 4 was analyzed, it was determined that there were significant differences in terms of attack errors, blocked attack, bad attacks, good attack, numbers of attack, coverage and number of total attacks depending upon the positions of the players $(\mathrm{p}<.05)$. According to this, hitters had lower averages rather than the opposite spikers, middle blockers had higher averages, and opposite spikers had higher averages rather than the medium blockers and setters in terms of attack errors, blocked attack, and number of attacks. In terms of coverage and total number of attacks, it was determined that hitters had higher averages than the medium blockers and setters and opposite spikers had higher averages rather than the setters.

\section{Discussion}

Volleyball teams' getting most of the scores from attack makes this technical skill remarkable (Challoumas \& Artemiou, 2018). Therefore, the situations that appear behind the successful and failed attack have become the concern of sports scientists and trainers.

According to the findings, when Table 2 was analyzed, it was noticed that the average of the attack errors performed by the players in all positions during the session was $3.67(\mathrm{Sd}=4.566)$, the average for the good attack was $5.86(\mathrm{Sd}=6.416)$, and the average for the bad attacks was $11.44(\mathrm{Sd}=12.859)$.

When Table 3 was analyzed, it was determined that there were significant differences in all attacks performed by the Turkish players and foreign-national players $(\mathrm{p}<0.05)$. According to this, attack errors $\left(M_{\text {Turkish }}=2.44\right.$; $\left.M_{\text {foreigner }}=6.44\right)$, blocked attack $\left(M_{\text {Turkish }}=2.44 ; M_{\text {foreigner }}=6.76\right)$, and bad attacks $\left(M_{\text {Turkish }}=7.25 ; M_{\text {foreigner }}=20.92\right)$ of the Turkish players were found to be lower than the foreign-nationality players.

When Table 4 was analyzed, it was determined that there were significant differences in terms of attack errors, blocked attack, bad attacks, good attack, numbers of attack, coverage and number of total attacks depending upon the positions of the players $(\mathrm{p}<.05)$. According to this, hitters had lower averages rather than the opposite spikers, middle blockers had higher averages, and opposite spikers had higher averages rather than the medium blockers and setters in terms of attack errors, blocked attack, and number of attacks. In terms of coverage and 
total number of attacks, it was determined that hitters had higher averages than the medium blockers and setters and opposite spikers had higher averages rather than the setters.

According to the results of the research, it was necessary to test several hypotheses in order to find the factors determining the quality of the attack. Costa et al. emphasized that emphasized that the percentage of elite male volleyball players' receiving the service perfect was proportional with the score taken from the attack and fast attack (Costa et al., 2017). In a study, it was determined that efficient service decreased the quality of receiving the service and this decreased the efficiency of attack (Costa et al., 2011; Castro, Souza, \& Mesquita, 2011).

In today's volleyball, attack has become so remarkable that Sato et al. developed a block machine for perfecting this skill, and tested its validity (Sato et al., 2017). During the attack, several coverage systems are used for getting the blocked balls into the game again (Hileno, Alcaraz, Busca, Salas, \& Camerino, 2018). In another study, Costa et al. indicated that efficiency of attack could change depending upon the double and triple block (Costa et al., 2014).

It was emphasized in another study that attack efficiency of the elite male players was more efficient in $1^{\text {st }}$ tempo, namely fast, attacks (Costa et al., 2011). Afonso et al. suggested that evaluation of attack efficiency in middle blockers well by the rival blockers was fairly determinative for the fast attack (Afonso \& Mesquita, 2011).

Challoumas and Artemiou emphasized the importance of the score taken by the attack upon winning the match, and expressed that the studies to be carried upon developing vertical leaping and attack technique would improve the attack performance (Challoumas \& Artemiou, 2018). Medeiros, Mesquita, Marcelino \& Palao stated that attack efficiency was highly relational with the technique and age (Medeiros, Mesquita, Marcelino, \& Palao, 2014). Nikos and Elissavet reported that the number of score from the attack increased as the efficiency of the setter increased (Nikos \& Elissavet, 2011).

Castro et al. examined the relationship between defense and attack and determined that bad quality of the ball from the defense especially decreased the quality of fast attack quality (Castro \& Mesquita, 2010). Silva et al. found in their research that attack error had a significant role in teams' winning or losing the match (Silva, Lacerda \& Joao, 2013). Marcelino, Sampaio \& Mesquita reported that the scores at the end of the sets were more important, and therefore this period should be managed more elaborately in terms of technique and tactic. Furthermore, training the players in a way similar to the real with selected drills at the end of the trainings was emphasized to be more beneficial for the players (Marcelino, Sampaio, \& Mesquita 2012). Due to these reasons, it is necessary to have a more disciplined and long-period work-outs at the end of the trainings considering the factors requiring to be more successful in attack. During the session, efficient attack work-outs related to the weaknesses and strengths of the rivals in training programs. In conclusion, success components of attack are broad in content (such as good technique and tactic, productive performance, efficient setter, attack without block, efficient receiving of the service, good attack, etc.). it was emphasized in several studies that the scores taken at the end of sets and match were remarkable, and the scores in these stages were efficient upon the score of the match. In this sense, $20^{\text {th }}$ scores could be named as the golden scores, and it could be noticed that opposite spikers and foreign-national players took more responsibility in this critical period.

In this sense, this study could be considered as remarkable for physical education and sport scientists because the researches carried out on the need of volleyball players for attack performance analyses during the match were limited. Furthermore, this study could be mentioned as having a quality shedding light on the further studies.

Due to these reasons, technic-tactic work-outs and repetitions in matches could cause the improvement of leaping ability contributing upon the acceleration of neuro-muscularity and strengthening of the muscles. The research should consider this, should discover new and specific usability styles and expectation movements, and should regard gaming dynamics more profoundly.

\section{References}

Afonso, J., \& Mesquita, I. (2011). Determinants of block cohesiveness and attack efficacy in high-level women's $\begin{array}{lllll}\text { volleyball. European Journal of Sport } & \text { Science, } & 11(1), & \text { 69-75. }\end{array}$ https://doi.org/10.1080/17461391.2010.487114

Alptekin, A., Acet, N., \& Korkmaz, H. (2016). Voleybolda yüzen servis tekniğinin kinematik analizi. International Journal of Science Culture and Sport, 4(1), 51-58. https://doi.org/10.14486/intJSC5533

Bazyler, C. D., Mizuguchi, S., Sole, C. J., Suchomel, T. J., Sato, K., Kavanaugh, A. A., DeWeese, B. H., \& Stone, M. H. (2018). Jumping performance is preserved but not muscle thickness in collegiate volleyball players after a taper. Journal of Strength and Conditioning Research, 32(4), 1020-1028. https://doi.org/10.1519/JSC.0000000000001912 
Castro, J. M., \& Mesquita, I. (2010). Analysis of the attack tempo determinants in volleyball's complex II-a study on elite male teams. International Journal of Performance Analysis in Sport, 10(3), 197-206. https://doi.org/10.1080/24748668.2010.11868515

Castro, J., Souza, A., \& Mesquita, I. (2011). Attack efficacy in volleyball: Elite male teams. Perceptual and Motor Skills, 113(2), 395-408. https://doi.org/10.2466/05.25.PMS.113.5.395-408

Challoumas, D., \& Artemiou, A. (2018). Predictors of attack performance in high-level male volleyball players. International Journal of Sports Physiology and Performance, 24, 1-23. https://doi.org/10.1123/ijspp.2018-0125

Costa, G. C., Caetano, R. C. C., Ferreira, N. N., Junqueira, G., Afonso, J., Costa, P., \& Mesquita, I. (2011). Determinants of attack tactics in youth male elite volleyball. International Journal of Performance Analysis in Sport, 11(1), 96-104. https://doi.org/10.1080/247486668.2011.11868532

Costa, G. C., Castro, H. O., Evangelista, B. F., Malheiros, L. M., Greco, P. J., \& Ugrinowitsch, H. (2017). Predicting factors of zone 4 attack in volleyball. Perceptual and Motor Skills, 124(3), 621-633. https://doi.org/10.1177/0031512517697070

Costa, G. D. T., Afonso, J., Barbosa, R. V., Coutinho, P., Mesquita, I. (2014). Predictors of attack efficacy and attack type in high-level Brazilian women's volleyball. Kinesiology, 46(2), 242-248.

Costa, G. D. T., Mesquita, I, Greco, P. J., Ferreira, N. N., Moraes, J. C. (2011). Relation service, reception and attack in male junior volleyball. Motriz-Revista De Educacao Fisica, 17(1), 11-18. https://doi.org/10.5016/1980-6574.2011v17n1p11

Frohner, B. (1989). Volleyball game theory and drills: Effective training and strategies. Germany: Sport Book Pub.

Giannopoulos, N., Vagenas, G., Noutsos, K., Barzouka, K., \& Bergeles, N. (2017). Somatotype, level of competition, and performance in attack in elite male volleyball. Journal of Human Kinetics, 58, 131-140. https://doi.org/10.1515/hukin-2017-0082

Häyrinen, M., \& Tampouratzis, K. (2012). Differences between winning and losing teams in top-level female beach volleyball. World Congress of Performance Analysis of Sport IX. University of Worcester, UK.

Hileno, R., Alcaraz, A. G., Busca, B., Salas, C., \& Camerino, O. (2018). What are the most widely used and effective attack coverage systems in men's volleyball? Journal of Human Kinetics, 62, 111-121. https://doi.org/10.1515/hukin-2017-0163

Marcelino, R. O., Sampaio J. E., \& Mesquita, I. M. (2012). Attack and serve performances according to the match period and quality of opposition in elite volleyball matches. The Journal of Strength and Conditioning Research, 26(12), 3385-3391. https://doi.org/10.1519/JSC.0b013e3182474269

Medeiros, I. A. A., Mesquita, I. M., Marcelino, R. O., \& Palao, M. J. (2014). Effects of technique, age and player's role on serve and attack efficacy in high level beach volleyball players. International Journal of Performance Analysis in Sport, 14(3), 680-691. https://doi.org/10.1080/24748668.2014.11868751

Nikos, B., \& Elissavet, N. M. (2011). Setter's performance and attack tempo as determinants of attack efficacy in Olympic-level male volleyball teams. International Journal of Performance Analysis in Sport, 11(3), 535-544. https://doi.org/10.1080/24748668.2011.11868571

Pérez Turpin, J. A., Cortell-Tormo, J. M., Suarez-Liorca, C., Chincilla-Mira, J. J., \& Cejuela-Anta, R. (2009). Gross movement patterns in elite female beach volleyball. Kinesiology, 41(2), 212-219.

Puhl, J., Case, S., Fleck, S., \& Van Handel, P. (1982). Physical and physiological characteristics of elite volleyball players. Research Quarterly for Exercise and Sport, 53(3), 257-262. https://doi.org/10.1080/02701367.1982.10609351

Sato, K., Watanabe, K., Muzino, S., Manabe, M., Yano, H., \& Iwata, H. (2017). Development and assessment of a block machine for volleyball attack training. Advanced Robotics, 31(21), 1144-1156. https://doi.org/10.1080/01691864.2017.1388192

Sentuna, M. (2005). Discrimination of winning and losing with defence and attack performances. Ankara Üniversitesi Spor Bilimleri Fakültesi Spormetre Dergisi, III(2), 85-92.

Sheppard, J. M., Cronin, J. B., Gabbett, T. J., McGuigan, M. R., Etxebarria, N., \& Newton R. U. (2008). Relative importance of strength, power, and anthropometric measures to jump performance of elite volleyball 
players. Journal of Strength and Conditioning Research, 22(3), 758-765. https://doi.org/10.1519/JSC.0b013e318a8440

Sheppard, J. M., Gabbet, T. J., \& Stanganelli, L. C. (2009). An analysis of playing positions in elite men's volleyball: considerations for competition demands and physiologic characteristics. Journal of Strength and Conditioning Research, 23(6), 1858-1866. https://doi.org/10.1519/JSC.0b013e3181b45c6a

Sheppard, J. M., Gabbett, T., Taylor, K. L., Dorman, J., Lebedew, A. J., \& Borgeaud, R. (2007). Development of a repeated-effort test for elite men's volleyball. International Journal of Sports Physiology and Performance, 2(3), 292-304.

Silva, M., Lacerda, D., \& Joao, P. L. (2013). Match analysis of discrimination skills according to the setter attack zone position in high level volleyball. International Journal of Performance Analysis in Sport, 13(2), 452-460. https://doi.org/10.1080/24748668.2014.11868735

\section{Copyrights}

Copyright for this article is retained by the author, with first publication rights granted to the journal.

This is an open-access article distributed under the terms and conditions of the Creative Commons Attribution license (http://creativecommons.org/licenses/by/4.0/). 